\title{
Health status among black African-born women in Kansas City: a preliminary assessment
}

Florence M. Ndikum-Moffor ${ }^{1}$, Babalola Faseru ${ }^{1,3^{*}}$, Melissa K. Filippi ${ }^{3}$, Hou Wei $^{2}$ and Kimberly K. Engelman ${ }^{1}$

\begin{abstract}
Background: Health information and statistics for Black foreign-born women in the United States are under-reported or not available. Black foreign-born women typically are classified under the general category of African American, ignoring the heterogeneity that exists in the United States Black population. It is important to identify health issues and behaviors of African-born women to effectively address health disparities.

Methods: Black African-born women $(\mathrm{N}=29), 20$ years or older completed a survey about general and women's health, health history, acculturation, lifestyle, social and health challenges, beliefs about breast cancer. Data were analyzed using SPSS 14.0 software. Categorical variables were summarized with frequencies and percentages and continuous variables were summarized with means and standard variation. A Likert scale (strongly agree, agree, disagree, and strongly disagree) was used to assess beliefs about breast cancer.
\end{abstract}

Results: Most (71.4\%) participants had a high school education or more, $70 \%$ were employed, and $50 \%$ had health insurance. Two-thirds received health care from primary care doctors, $20.7 \%$ from health departments, and $39.3 \%$ got annual checkups. Lack of jobs, healthcare cost, language barrier, discrimination, and child care were the top social issues faced by participants. High blood pressure, obesity, oral health, HIV/AIDS, and diabetes were indicated as the most common health problems. The percent of participants (60\%) that had not had a mammogram within the previous 2 years was more than the state average ( $24 \%$ ) for women 40 years and older reported by the Kansas Department of Health and Environment. The percent of participants (40 \%) that had a mammogram within the previous 2 years was lower than the national average (73.2\%) for African American women.

Conclusions: Study provides a snapshot of social concerns and health issues in an African population residing in Midwestern United States. Understanding the socio-cultural characteristics of this population is necessary to address health disparities.

Keywords: Women's health, Health disparities, African-born women's health

\section{Background}

\section{African-born women in the United States}

The African immigrant/refugee population in the United States doubled between 2000 and 2010, with the number of women growing from 396,510 to 761,677 [1-3], and women making up about $50 \%$ of the African immigrant/ refugee population [4]. While the health status for Black

\footnotetext{
*Correspondence: bfaseru@kumc.edu

${ }^{3}$ Department of Family Medicine, Center for American Indian Community Health, University of Kansas Medical Center, 3901 Rainbow Boulevard, Kansas City, KS 66160, USA

Full list of author information is available at the end of the article
}

women is reported in general [5], health information and statistics for Black foreign-born women are underreported or not available [6], and are not distinguished from Black United States-born women.

Thus, there is a paucity of information about the health issues in this population of Black women. Black women in the United States continue to have the highest rates of breast cancer deaths. Various reasons for this increased mortality have been suggested including low screening rates, lack of awareness, and inadequate treatment [7]. However, data that describe breast cancer in black women in the US lump together US-born and foreign-born black women, undermining the 
differences in socio-cultural and psychosocial characteristics that may influence their perceptions and attitudes towards breast cancer diagnosis and utilization of screening services. Black African-born women have socio-economic and cultural beliefs that could differentially affect their lifestyle and health care access compared to Black United States-born women [6]. Additionally, some immigration laws make it more difficult for immigrants to gain access to health care compared to native United States citizens; for example, non-citizens who are legal residents are not Medicaid eligible until after 5 years as legal residents [8]. Recording and reporting health statistics data only by (black) race masks differences within the Black population and provides inadequate information to develop effective programs [9]. To remedy this conundrum, the United States Department of Health and Human Services created an African Data Work Group to collect, organize, share, and identify gaps in knowledge and information on African immigrants and refugees [10]. The objectives of this study were to gather information about health issues and health care access among African immigrant and refugee women, and assess women's knowledge of and awareness about breast cancer.

\section{Methods}

Black African-born women $(\mathrm{N}=29)$ originally from countries in West, Central and East Africa, and living in the Kansas City (KC) metropolitan area completed a survey about general health, women's health, oral health, diet and exercise, acculturation, health history, and beliefs about breast cancer. Participants were recruited during an educational event to increase breast and cervical cancer awareness among immigrant and refugee women from Africa. The event was advertised through social media, and by posting flyers at local Africanchurches, grocery stores, hair salons, and community organizations. The event was also advertised by word of mouth. While questions about health status and health care access were addressed to all participants, questions about breast cancer screening including mammography were addressed to women aged 35 and older. Informed consent to participate in the study was obtained from participants verbally before they completed the survey. The Institutional Review Board of the University of Kansas Medical Center approved the study. Data were analyzed using SPSS 14.0 software. Categorical variables were summarized with frequencies and percentages and continuous variables were summarized with means and standard variation. A four-level Likert scale (strongly agree, agree, disagree, and strongly disagree) was used to assess beliefs about breast cancer.

\section{Results and discussion}

Participants were $20-68$ years old (mean age $=39$ years), had lived in the United States from 1 to 17 years; $29 \%$ had lived in the United States for just 1 year and $29 \%$ had lived in the United States for over 10 years. Most (70 \%) were employed and $71.4 \%$ had more than a high school education. Over half (55.6\%) of the participants indicated they always spoke a language other than English outside their homes. Two-thirds were married or living with a partner, and $78.6 \%$ had at least one child (Table 1).

\section{Health care access}

Access to health care, cancer screening and dental services by participants are summarized in Table 2. Noteworthy is that only $34.6 \%$ of participants had private

Table 1 Participant demographics $(\mathrm{N}=\mathbf{2 9})$

\begin{tabular}{lrl}
\hline Characteristic & N & Percent \\
\hline Age (in years, mean, SD) & 23 & $(39.0 \pm 11.4$; mean age) \\
Country of origin & 26 & \\
Cameroon & 10 & 38.5 \\
Kenya & 12 & 46.1 \\
Nigeria & 4 & 15.4 \\
Years in the US & 28 & \\
1 year & 8 & 28.6 \\
2-4 years & 5 & 17.8 \\
5 years & 3 & 10.7 \\
6-10 years & 4 & 14.3 \\
Over 10 years & 8 & 28.6 \\
Current living situation & 28 & \\
Married/living with a partner & 19 & 67.9 \\
Divorced/separated/widowed & 5 & 17.9 \\
Never married & 2 & 7.1 \\
Other & 2 & 7.1 \\
Highest educational attainment & 27 & \\
Elementary/grade school & 2 & 7.4 \\
High school graduate/GED & 4 & 14.8 \\
Some college & 1 & 3.7 \\
2-year college graduate (AA degree) & 9 & 33.3 \\
4-year college graduate (BA/BS degree) & 8 & 29.6 \\
Graduate degree & 3 & 11.1 \\
Employment status & 27 & \\
Employed & 19 & 70.4 \\
Self-employed & 2 & 7.4 \\
Out of work for <1 year & 1 & 3.7 \\
Stay home mom & 2 & 7.4 \\
Unable to work & 3 & 11.1 \\
Children & 28.6 \\
Yes & & \\
\hline & 22 & \\
\hline
\end{tabular}

Italicized texts represent total number of respondents per characteristic 
Table 2 Health care access $(\mathbf{N}=29)$

\begin{tabular}{|c|c|c|}
\hline Question & $\mathbf{N}$ & Percent \\
\hline How would you rate your health? & 29 & \\
\hline Very good & 11 & 37.9 \\
\hline Good & 14 & 48.3 \\
\hline Fair & 4 & 13.8 \\
\hline Where do you get most of your health care? & 29 & \\
\hline Community health clinic & 2 & 6.9 \\
\hline Primary care doctor & 18 & 62.1 \\
\hline Free clinic & 2 & 6.9 \\
\hline Health department & 6 & 20.7 \\
\hline Other & 1 & 3.4 \\
\hline When was your last routine check up? & 29 & \\
\hline Less than a year & 11 & 39.3 \\
\hline $1-2$ years & 10 & 35.7 \\
\hline $2-5$ years & 1 & 3.6 \\
\hline 5 or more years & 2 & 7.1 \\
\hline Don't know/not sure & 3 & 10.7 \\
\hline Never & 1 & 3.6 \\
\hline How long since last teeth cleaning? & 28 & \\
\hline Less than a year & 10 & 35.7 \\
\hline $1-2$ years & 6 & 21.4 \\
\hline $2-5$ years & 3 & 10.7 \\
\hline 5 or more years & 1 & 3.6 \\
\hline Never & 8 & 28.6 \\
\hline Do you currently have health insurance? & 26 & \\
\hline No insurance & 11 & 42.3 \\
\hline Private insurance & 9 & 34.6 \\
\hline Other & 4 & 15.4 \\
\hline Prefer not to respond & 2 & 7.7 \\
\hline Have you ever had a clinical breast exam? & 26 & \\
\hline Yes & 19 & 73.1 \\
\hline How long since your last clinical breast exam? & 25 & \\
\hline Less than a year & 7 & 28.0 \\
\hline $1-2$ years & 6 & 24.0 \\
\hline $2-5$ years & 2 & 8.0 \\
\hline 5 or more years & 3 & 12.0 \\
\hline Never & 4 & 16.0 \\
\hline Not sure/don't know & 3 & 12.0 \\
\hline Have you ever had a mammogram? & 22 & \\
\hline Yes & 10 & 45.4 \\
\hline How long since your last mammogram? & 10 & \\
\hline Less than a year & 3 & 30.0 \\
\hline $1-2$ years & 1 & 10.0 \\
\hline $2-5$ years & 2 & 20.0 \\
\hline 5 or more years & 4 & 40.0 \\
\hline Have you ever had a Pap test? & 27 & \\
\hline Yes & 20 & 74.1 \\
\hline How long since your last Pap test? & 25 & \\
\hline Less than a year & 11 & 40.7 \\
\hline $1-2$ years & 5 & 18.5 \\
\hline
\end{tabular}

Table 2 continued

\begin{tabular}{lcc}
\hline Question & N & Percent \\
\hline 2-5 years & 2 & 7.4 \\
5 or more years & 2 & 7.4 \\
Never & 5 & 18.5 \\
Not sure/don't know & 2 & 7.4 \\
\hline
\end{tabular}

Italicized texts represent total number of respondents per question

health insurance and $15.4 \%$ had other types of insurance coverage, $28.6 \%$ had never been to a dentist, and only 3 of 10 women (40 and older) were up-to-date on their mammograms. The percent of participants $(60 \%)$ that had not had a mammogram within the previous 2 years was more than the state average $(24 \%)$ for women 40 years and older reported by the Kansas Department of Health and Environment. The percent of participants $(40 \%)$ that had a mammogram within the previous 2 years was lower than the national average (73.2 \%) for African American women [11], Majority of the study participants rated their health status as good or very good, and most had visited a primary care provider within the previous 2 years. It was not clear how these women pay for the health care services since $41 \%$ did not have any form of health care coverage. The percent of uninsured in the study population was over three times higher than the 3-year (2010-2013) average for people without insurance in Kansas (12.9\%), Missouri (14.0\%), and nationally for all races (15.8 \%) and for Blacks (19.8 \%) [12].

The high percent (41\%) of uninsured in the study population was surprising because $70 \%$ was employed, suggesting that some of the women may be under-employed or working for establishments or businesses that do not offer health care coverage, or they may not consider health insurance important as most countries in Africa run their health systems with payer fee. One study limitation is that immigration status was not requested. That information may have explained the reason for the high percent uninsured in this population as immigration status has been shown to influence access to health insurance and health care services [8]. The American Cancer Society reported that nationally, $68 \%$ of uninsured women in the United States did not get mammograms within the past 2 years [13]; thus, lack of health insurance is a huge barrier to regular breast cancer screening.

\section{Breast cancer knowledge, risk perception, and assessment} Because of increasing rates of non-communicable diseases in African countries and in African-born individuals in the United States, some sections of our survey focused on perceptions of cancer risk, and assessment of risk of breast and cervical cancer in our study population. 
Only $20 \%$ of participants agreed that they were not at risk of breast cancer. Most (92.9 \%) participants agreed that breast cancer can be treated if detected early, $72.4 \%$ strongly disagreed that breast cancer is a curse from God, and $53.5 \%$ either strongly agreed or agreed that breast cancer can disappear following prayer. A preliminary assessment of participants' cancer risks is summarized in Table 3. While Black African-born women, like black United States-born women, have a lower incidence of breast cancer than White women, the overall mortality from breast cancer in Black women is still highest among all racial/ethnic groups [10]. However, it is difficult to separate the contribution of African immigrants to the overall incidence reported for Blacks; peradventure there are some risk factors peculiar to this subgroup. Breast health programs that address prevention, diagnosis and treatment of breast cancer are scarce or non-existent in most countries in Sub-Saharan Africa [6]. Therefore, prior to their immigration to the United States, many Black African-born women would have very little knowledge of or exposure to breast health programs and standard breast cancer screening tests. This potential lack of breast cancer awareness among Black African-born women may increase the risk of late breast cancer diagnosis in this population.

\section{Social and health concerns}

Participants identified high blood pressure, obesity, oral health, HIV and diabetes as the most common health problems in their African community, similar to health issues among African American women [10]. Lack of jobs, health care cost, language barrier, discrimination, and child care were the top five social concerns in the African community. Black United States-born women also face challenges with racial discrimination, jobs and health care costs, but not the added burden of language barrier experienced by many Black African-born women-a barrier that limits their understanding of health issues, and their ability to adequately communicate with health care providers and navigate the health care system.

\section{Conclusions}

While the sample size for this study was small and participants were from a Midwestern African-born population, these preliminary results provide a snapshot of the

Table 3 Breast cancer risk

\begin{tabular}{|c|c|c|}
\hline Question & $\mathbf{N}$ & Percent \\
\hline Do you smoke? & 26 & \\
\hline No & 26 & 100 \\
\hline At what age did you have your first child? & 14 & \\
\hline 19-24 years & 7 & 50 \\
\hline $25-30$ years & 7 & 50 \\
\hline Have you been told by doctor or provider that you have breast cancer? & 27 & \\
\hline No & 27 & 100 \\
\hline Have anyone in your family, on your mother's side or father's side ever had breast cancer? & 27 & \\
\hline No & 22 & 81.5 \\
\hline Yes & 3 & 11.1 \\
\hline Don't know/not sure & 2 & 7.4 \\
\hline Have you ever had a breast biopsy? & 27 & \\
\hline No & 24 & 88.9 \\
\hline Have you been told by a doctor or health professional that you have dense breast tissue? & 28 & \\
\hline No & 26 & 92.8 \\
\hline Yes & 1 & 3.6 \\
\hline Don't know/not sure & 1 & 3.6 \\
\hline Have you ever had radiation therapy to the chest or neck area as treatment for another cancer? & 28 & \\
\hline No & 27 & 96.4 \\
\hline Don't know/not sure & 1 & 3.6 \\
\hline Including you, has anyone in your family ever been told or tested for hereditary breast cancer with changes in BRCA1/BRCA2 genes? & 28 & \\
\hline No & 22 & 78.6 \\
\hline Yes & 1 & 3.6 \\
\hline Don't know/not sure & 5 & 17.8 \\
\hline
\end{tabular}

Italicized texts represent total number of respondents per question 
health care access and needs of the larger population of African-born women in the United States because similar issues have been reported for African immigrants in various other regions of the United States [1, 6, 10]. Future studies are needed to examine in more detail the health issues in African-born individuals in the United States, identify socio-cultural characteristics that influence behavior and health, and develop interventions that are culturally tailored to this culturally heterogeneous group of Black people.

\section{Authors' contributions}

FNM participated in the design, acquisition of data, interpretation of data and preparation of the manuscript. BF participated in the analysis and interpretation of data and review of the manuscript. MF participated in interpretation of data and revising manuscript critically for important intellectual content. HW performed the data analysis. KE participated in the study design, and critical review of manuscript. All authors read and approved the final manuscript.

\section{Author details}

${ }^{1}$ Department of Preventive Medicine and Public Health, University of Kansas Cancer Center, Center for American Indian Community Health, University of Kansas Medical Center, 3901 Rainbow Boulevard, MS 1056, Kansas City, KS 66160, USA. ${ }^{2}$ Department of Preventive Medicine and Public Health, Center for American Indian Community Health, University of Kansas Medical Center, 3901 Rainbow Boulevard, Kansas City, KS 66160, USA. ${ }^{3}$ Department of Family Medicine, Center for American Indian Community Health, University of Kansas Medical Center, 3901 Rainbow Boulevard, Kansas City, KS 66160, USA

\section{Acknowledgements}

This project would not be possible without the study participants. We would like to thank them. The breast and cervical cancer educational event at which participants were surveyed was organized by CommuCare Services Inc, a local non-profit organization.

\section{Compliance with ethical guidelines}

\section{Competing interests}

The authors declare that they have no competing interests.

Received: 28 May 2014 Accepted: 21 September 2015

Published online: 05 October 2015

\section{References}

1. Sheppard VB, Christopher J, Nwabukwu I. Breaking the silence barrier: opportunities to address breast cancer in African-born women. J Natl Med Assoc. 2010;102:461-8.

2. Martin DC, Yankay JE. Refugees and Asylees: 2012. Office of Immigration Statistics, Department of Homeland Security. 2013.

3. Immigration Policy Center. African Immigrants in America: A Demographic Overview. 2012. http://www.immigrationpolicy.org/just-facts/ african-immigrants-america-demographic-overview. Accessed 28 May 2014

4. U.S. Department of Homeland Security. Yearbook of Immigration Statistics 2012.

5. Agency for Healthcare Research and Quality. National Healthcare Disparity Report, 2011. In: U.S. Department of Health and Human Services, ed. 2012

6. Venters H, Gany F. African immigrant health. Journal of immigrant and minority health/Center for Minority Public Health. 2011:13:333-44

7. The American Cancer Society, Cancer Facts and Figures, 2015.

8. Ku L, Matani S. Left out: immigrants' access to health care and insurance. Health Aff (Millwood). 2001:20:247-56.

9. Borell LNCD, Conway FP, Terry MB. Influence of nativity status on breast cancer risk among U.S. black women. J Urban Health Bull NY Acad Med. 2006;83:211-20

10. U.S. Department of Health \& Human Services Office of Minority Health. National African Immigrant Project. http://minorityhealth.hhs.gov/templates/content.aspx? $|v|=2 \&|v| i d=66 \& \mid D=9093$. Accessed 28 May 2014.

11. Division of Cancer Prevention and Control, Centers for Disease Control and Prevention. http://www.cdc.gov/cancer/breast/statistics/screening. htm. Accessed 28 May 2014.

12. U.S. Census Bureau CPS, 2010 to 2013 Annual Social and Economic Supplements. Number and Percentage of People Without Health Insurance Coverage by State Using 2- and 3-Year Averages: 2009-2010 and 2011-2012. 2013 http://www.census.gov/hhes/www/hlthins/data/ incpovhlth/2012/tables.html. Accessed 28 May 2014.

13. The American Cancer Society, Breast Cancer Facts and Figures, 2013-2014. American Cancer Society, Surveillance and Health Services Research, 2013

\section{Submit your next manuscript to BioMed Central and take full advantage of:}

- Convenient online submission

- Thorough peer review

- No space constraints or color figure charges

- Immediate publication on acceptance

- Inclusion in PubMed, CAS, Scopus and Google Scholar

- Research which is freely available for redistribution 